\title{
TELOMERE LENGTH, COMORBIDITY, FUNCTIONAL, NUTRITIONAL AND COGNITIVE STATUS AS PREDICTORS OF 5 YEARS POST HOSPITAL DISCHARGE SURVIVAL IN THE OLDEST OLD
}

\author{
D. ZEKRY ${ }^{1}$, K.H. KRAUSE², I. IRMINGER-FINGER ${ }^{2}$, C.E. GRAF ${ }^{1}$, C. GENET$^{1}$, A.-M. VITALE${ }^{1}$, \\ J.-P. MICHEL', G. GOLD', F.R. HERRMANN'
}

\begin{abstract}
1. Department of Rehabilitation and Geriatrics, Geneva University Hospitals and University of Geneva, Thônex, Switzerland; 2. Pathology and Immunology Department, Geneva University Hospitals and University of Geneva, Geneva, Switzerland. Corresponding author: Dr. Dina Zekry, Department of Rehabilitation and Geriatrics Geneva University Hospitals, 3 , chemin du Pont-Bochet, Thônex, Switzerland. Telephone number: (0114122) 3056355 / Fax number: (0114122) 3056115, E-mail address: dina.zekry@ hcuge.ch
\end{abstract}

\begin{abstract}
Background: Telomere length has been considered in many cross-sectional studies as a biomarker of aging. However the association between shorter telomeres with lower survival at advanced ages remains a controversial issue. This association could reflect the impact of other health conditions than a direct biological effect. Objective: To test whether leukocyte telomere length is associated with 5-year survival beyond the impact of other risk factors of mortality like comorbidity, functional, nutritional and cognitive status. Design: Prospective study. Setting and participants: A population representative sample of 444 patients (mean age 85 years; $74 \%$ female) discharged from the acute geriatric hospital of Geneva University Hospitals (JanuaryDecember 2004), since then 263 (59.2\%) had died (December 2009). Measurements: Telomere length in leukocytes by flow cytometry. Results: In univariate model, telomere length at baseline and cognitive status were not significantly associated with mortality even when adjusting for age $\left(\mathrm{R}^{2}=9.5 \%\right)$ and gender $\left(\mathrm{R}^{2}=1.9 \%\right)$. The best prognostic predictor was the geriatric index of comorbidity (GIC) $\left(\mathrm{R}^{2}=8.8 \%\right.$; $\left.\mathrm{HR}=3.85\right)$ followed by more dependence in instrumental $\left(\mathrm{R}^{2}=5.9 \% ; \mathrm{HR}=3.85\right)$ and based $\left(\mathrm{R}^{2}=2.3 \% ; \mathrm{HR}=0.84\right)$ activities of daily living and lower albumin levels $\left(\mathrm{R}^{2}=1.5 \%\right.$; $\left.\mathrm{HR}=0.97\right)$. Obesity $\left(\mathrm{BMI}>30: \mathrm{R}^{2}=1.6 \%\right.$; $\left.\mathrm{HR}=0.55\right)$ was significantly associated with a two-fold decrease in the risk of mortality compared to BMI between 20-25. When all independent variables were entered in a full multiple Cox regression model $\left(\mathrm{R}^{2}=21.4 \%\right)$, the GIC was the strongest risk predictor followed by the nutritional and functional variables. Conclusion: Neither telomeres length nor the presence of dementia are predictors of survival whereas the weight of multiple comorbidity conditions, nutritional and functional impairment are significantly associated with 5-year mortality in the oldest old.
\end{abstract}

Key words: Telomere, aging, biomarker, mortality, survival.

\section{Introduction}

Telomeres are repetitive structures at the end of mammalian chromosomes and together with associated proteins they protect chromosome ends (1). In normal cells, a progressive telomere shortening accompany each cycle of replication (2) and there is a well-established gradual loss of telomere length in human peripheral blood with increasing age (3-7). In addition, most (8$10)$ but not all studies $(11,12)$ have shown a positive association between telomere length and overall survival in humans. Evidence accumulates that telomere shortening reflects lifestyle and predicts remaining lifespan by a direct biological effect. More recent findings suggest that telomere length may not be a strong biomarker of survival in older individuals, but may be an informative biomarker of healthy aging (13). However, there are few longitudinal data examining the prognostic value of leukocyte telomere length in the context of other health variables such as comorbidity, functional, nutritional and cognitive status.

Thus, we sought to investigate the relationship between leukocyte telomere length and mortality among a population of very old, acutely ill patients discharged from a geriatric hospital in a prospective cohort study and to determine whether leukocyte telomere length provides incremental prognostic value beyond existing other markers of risk.

\section{Methods}

\section{Patients and data collection}

We carried out a prospective study in a 300-acute bed geriatric hospital (HOGER) where $22.7 \%$ are direct admission from the community, $54.0 \%$ are referred by the emergency unit and $23.3 \%$ are transferred from other divisions of Geneva University Hospitals, Switzerland. Patients and data collection have been described elsewhere (14-16). Briefly, a representative sample of all patients aged 75 years and over, consecutively admitted in 2004 were selected by randomization, with a sampling fraction of $30 \%$ using a computer generated randomization table. The local ethics committee approved the protocol, and patients, their families or legal representatives provided signed written informed consent. Demographic data for the patients studied did not significantly differ from all patients admitted to HOGER at the same period. Our sample was therefore representative of all patients admitted to this hospital, demonstrating the reliability of the randomization procedure used in this study.

Medical history was recorded on a standardized form and the same geriatrician carried out a comprehensive geriatric 
assessment on all patients. Annual follow-up was carried out with the same assessment over a five-year period.

\section{Sociodemographic data}

The data recorded included age, sex, native language, marital status, living arrangement and educational level.

\section{Telomere length measurements}

Telomere length were determined as a function of fluorescence intensity, using an FITC-labeled peptide nucleic acid (PNA) probe (FITC-coupled) supplied with the telomere PNA /FITC for flow cytometry kit by DAKO (http://www. dakousa.com/prod_downloadpackageinsert.pdf?objectid=11479 1002).

In situ hybridization: Lymphocytes were prepared for hybridization in the presence of hybridization solution without probe or in hybridization solution containing fluoresceinconjugated PNA telomere probe, as described in Hultdin et al. (17). Flow cytometry: Labelled cells were analyzed by flow cytometry. Homogeneous lymphocyte subpopulations were identified. DNA was labelled with DAPI to identify cell populations with similar DNA content, with gating on the G1 population. FITC-labelled cells were counted in the gated population. As an internal control, telomere length was measured in a standard cell line (HL60), which allowed normalizing the flow cytometric measurements with respect to day to day variations. Image analysis was performed with the same flow cytometer (FACS, Fluorescence Activated Cell Sorting; Partec PAS Flow Cytometer Galaxy, USA) in each case. Mean telomere fluorescence intensity was calculated as the difference between the fluorescence signal obtained with samples hybridized with the Telomere PNA Probe/FITC and the fluorescence signal obtained with a sample of the same cells incubated with the hybridization solution without probe. Results are expressed as telomere length index, which is the fluorescent signal obtained in the patient cells divided by the fluorescent signal of the control HL-60 cells. Thus, a telomere length index of 1 indicates a telomere length in the patient sample identical to the one observed in HL-60 cells. The intraassay coefficient of variance of this measurement was less than $2 \%$.

\section{Nutritional assessment}

Body mass index $\left(\mathrm{BMI} \mathrm{kg} / \mathrm{m}^{2}\right)$ was determined and the short version of the Mini Nutritional Assessment (MNA) (score ranging from 0 to $14, \geq 12$ being normal) administered on admission, by the same nurse in each case (18). The reference period for the MNA was two weeks before admission. Albumin blood level (g/l) was measured by bromocresol purple dyebinding method.

\section{Functionality}

Base and Instrumental Activities of Daily Living (ADL, IADL) $(19,20)$ scores were determined as a function of patient status two weeks before admission, based on the patient's medical history or information supplied by an informal or formal carer.

\section{Assessment of Comorbidity}

From our previous work on this cohort (21) the best prognostic predictor of 5-year mortality was the Geriatric Index of Comorbidity (GIC) (22) class 4 multiplying the risk of death by 4 , thus we used this comorbidity score in this study. The same geriatrician calculated this score for each patient, via an extensive review of the patient's medical records and administrative data for diagnoses established at or before enrolment in this study and by standardized interviews with patients and surrogates. The GIC classifies patients into four classes of increasing somatic comorbidity.

\section{Cognitive diagnosis}

The same neuropsychologist assessed all subjects for clinical dementia, The MMSE (23) and the Short Cognitive Evaluation Battery were used $(24,25)$. Based on screening results, the neuropsychologist then carried out a comprehensive standardized neuropsychological assessment to determine the etiology and severity of clinical dementia, as previously described $(14,15)$. The formal clinical criteria used for diagnosis were those of the DSM IV-TR (26), NINCDSADRDA (27) and NINDS-AIREN (28). Cerebral imaging was also carried out.

\section{Outcome}

The outcome of interest was death by December 31, 2009, that means an average 60 months (five years) of follow-up. This information was obtained through yearly phone calls to the patient, his family and/or his general practitioner. Mortality data was also confirmed through access to the population registrar of the State of Geneva.

\section{Statistical methods}

We checked the normality of the data distribution with skewness and kurtosis tests, and carried out standard transformations to normalise non-Gaussian variables. Data for continuous variables are presented as means \pm 1 standard deviation (SD).

First, we measured the univariate relationship between each independent variable and 5-year mortality. We used Cox proportional hazards models to take into account the time to the event. The independent variables assessed as possible predictors included age, sex, telomere length, nutritional and functional status before admission (MNA, ADL and IADL scores), albumin level and BMI at admission, comorbidity score and cognitive diagnosis (normal or demented). We also used Kaplan-Meier survival curves to examine the performance of the independent variables over time. We then entered all independent variables and 5-year mortality as dependent variable in multivariate Cox regression. Hazards ratios (HR) 
along with their $95 \%$ confidence intervals (CI) were calculated. Continuous variables were either included as such or dichotomized, using the lower cut-off value (MNA, ADL and IADL). As it was not possible to normalize telomere length and BMI scores, they were categorized into tertiles for telomere length (lower tertile $\leq 0.49$ (95\% CI 0.44-0.52), reference tertile: $0.49-0.77$ and upper tertile $>0.77$ (95\% CI 0.72-0.82)) and quartiles for BMI $\left(<20 \mathrm{~kg} / \mathrm{m} 2,20-25 \mathrm{~kg} / \mathrm{m}^{2}=\right.$ reference, $25-30 \mathrm{~kg} / \mathrm{m}^{2}$ and $\left.>30 \mathrm{~kg} / \mathrm{m}^{2}\right)$. The proportional-hazards assumption was successfully tested for telomere length based on Schoenfeld residuals. Pseudo R-squared $\left(\mathrm{R}^{2}\right)$ which provides information on the amount of variance explained by the model were computed using the Stata "str2ph" command based on the Royston's modification of O'Quigley, Xu \& Stare's modification of Nagelkerke's $\mathrm{R}^{2}$ statistic for proportionalhazards models with censored survival data (29). The comorbidity score applied, the GIC is predefined into four classes. As there were only $2 \%$ of the patients classified as class 1 by the GIC, they were combined with class 2 for the analysis and considered as the standard. Statistical analyses were performed with Stata software version 11, TX, US.

\section{Results}

556 patients were randomized, 523 were successfully enrolled and 496 survived to hospital discharge (27 died during the hospitalization), 444 patients had full data and were included in this study (mean age $85.3 \pm 6.7 ; 74 \%$ women). Of the 444 patients, 263 died during the five years after discharge $(59.2 \%)$. The distribution of patients according to sex, telomere length, BMI, MNA, albumin level, ADL, IADL, comorbidity score and cognitive function on baseline and those who died after 5 years of follow-up are described in Table 1 .

\section{Univariate and multiple Cox proportional hazards modeling (Table 2)}

In univariate analysis, 5 year-mortality was significantly associated with age, each supplementary year added $7 \%$ to the risk of death $\left(\mathrm{R}^{2}=9.5 \%, \mathrm{HR}=1.07,95 \% \mathrm{CI}=1.05-1.09\right)$; being a men increased the risk by 1.5 fold $\left(\mathrm{R}^{2}=1.9 \%, \mathrm{HR}=\right.$ $1.52,95 \% \mathrm{CI}=1.17-1.98)$. The telomere length, the cognitive status and the MNA score were not predictor of the outcome.

The best prognostic predictor was the GIC class $4\left(\mathrm{R}^{2}=\right.$ $8.8 \%, \mathrm{HR}=1.07 \mathrm{HR}=3.85,95 \% \mathrm{CI}=2.29-6.47)$. After 5 years, approximately $80 \%$ of the high score patients were already deceased, compared with less than $40 \%$ in the lowest scores.

The albumin level $\left(\mathrm{R}^{2}=1.5 \%, \mathrm{HR}=0.97,95 \% \mathrm{CI}=0.95-\right.$ $0.99)$; the $\mathrm{ADL}\left(\mathrm{R}^{2}=2.3 \%, \mathrm{HR}=0.84,95 \% \mathrm{CI}=0.76-0.93\right)$ and IADL $\left(\mathrm{R}^{2}=5.9 \%, \mathrm{HR}=0.87,95 \% \mathrm{CI}=0.82-0.92\right)$ were negatively associated, that means lower albumin levels and more dependence in based and instrumental activities of daily living were associated with greater mortality. Each supplementary gram of albumin added $3 \%$ of additional protective risk against death. Curiously, obesity $\left(\mathrm{BMI}>30: \mathrm{R}^{2}\right.$
$=1.6 \%, \mathrm{HR}=0.55,95 \% \mathrm{CI}=0.35-0.86)$ was significantly associated with a half lower mortality risk compared to BMI between 20 and 25 considered as the reference level. KaplanMeier survival curves of the independent risk factors are shown in figure 1.

\section{Table 1}

Distribution of patients according to sex, telomere length, BMI, MNA, albumin level, ADL, IADL, comorbidity score and cognitive function at baseline $(n=444)$ and those who died ( $n$ $=263$ ) after 5 years of follow-up

\begin{tabular}{|c|c|c|c|c|}
\hline & \multicolumn{2}{|c|}{$\begin{array}{l}\text { Patients included } \\
\text { at baseline }\end{array}$} & \multicolumn{2}{|c|}{$\begin{array}{l}\text { Patients dead after } \\
5 \text { years of follow-up }\end{array}$} \\
\hline & $\mathbf{N}$ & $\%$ & $\mathbf{N}$ & $\%$ \\
\hline Age $($ mean $\pm \mathrm{SD})$ & $85.2 \pm 6.7$ & - & $86.8 \pm 6.5$ & - \\
\hline Female/Male & $328 / 116$ & $74.0 / 26.0$ & $183 / 80$ & $69.6 / 30.4$ \\
\hline \multicolumn{5}{|l|}{$\begin{array}{l}\text { Telomere length } \\
(\text { median } \pm \text { iqr, } 0.63 \pm 0.49)\end{array}$} \\
\hline lower tertile $(\leq 0.49)$ & 147 & 33.1 & 109 & 41.4 \\
\hline medium tertile $(0.49-0.77)$ & 147 & 33.1 & 87 & 33.1 \\
\hline upper tertile $(>0.77)$ & 150 & 33.8 & 67 & 25.5 \\
\hline \multicolumn{5}{|l|}{ BMI $(\mathrm{kg} / \mathrm{m} 2)$} \\
\hline$<20$ & 94 & 21.2 & 62 & 23.6 \\
\hline $20-25$ & 179 & 40.3 & 109 & 41.5 \\
\hline $25-30$ & 115 & 25.9 & 69 & 26.2 \\
\hline$>30$ & 56 & 12.6 & 23 & 8.7 \\
\hline \multicolumn{5}{|l|}{ MNA } \\
\hline$<12$ & 337 & 75.9 & 200 & 76.0 \\
\hline$\geq 12$ & 107 & 24.1 & 63 & 24.0 \\
\hline \multicolumn{5}{|c|}{ Albumin level g/l (median \pm iqr, $33 \pm 8)$} \\
\hline$\leq$ median & 240 & 54.0 & 152 & 57.8 \\
\hline$>$ median & 204 & 46.0 & 111 & 42.2 \\
\hline \multicolumn{5}{|l|}{$\operatorname{ADL}($ median \pm iqr; $5 \pm 1)$} \\
\hline$\leq$ median & 106 & 23.9 & 75 & 28.5 \\
\hline$>$ median & 338 & 76.1 & 188 & 71.5 \\
\hline \multicolumn{5}{|l|}{ IADL (median \pm iqr; $4 \pm 3$ ) } \\
\hline$\leq$ median & 166 & 37.4 & 121 & 46.0 \\
\hline$>$ median & 278 & 62.6 & 142 & 54.0 \\
\hline \multicolumn{5}{|l|}{ GIC } \\
\hline Class $1+2$ & 43 & 9.7 & 18 & 6.8 \\
\hline Class 3 & 310 & 69.8 & 174 & 66.2 \\
\hline Class 4 & 91 & 20.5 & 71 & 27.0 \\
\hline Demented/cognitively normal & $190 / 254$ & $42.8 / 57.2$ & $121 / 142$ & $46.0 / 54.0$ \\
\hline
\end{tabular}

$\mathrm{BMI}=$ body mass index, $\mathrm{MNA}=$ mini nutritional assessment, $\mathrm{ADL}=$ base activities of daily living, IADL = instrumental activities of daily living, GIC = geriatrics index of comorbidity, $\mathrm{SD}=$ standard deviation, iqr $=$ inter quartile range. Bold entries $=$ relevant results.

When all variables were included in the full model while adjusting for age and sex $(\mathrm{R} 2=21.4 \%)$, the GIC class $4(\mathrm{HR}=$ $2.45,95 \% \mathrm{CI}=1.40-4.28)$ remained the best predictor independently associated with 5-year mortality followed by the IADL $(\mathrm{HR}=0.91,95 \% \mathrm{CI}=0.84-0.98)$, the albumin level $(\mathrm{HR}=0.97,95 \% \mathrm{CI}=0.95-1.00)$; the $\mathrm{BMI}>30(\mathrm{HR}=0.60$, $95 \% \mathrm{CI}=0.37-0.98)$; age $(\mathrm{HR}=1.06,95 \% \mathrm{CI}=1.03-1.08)$ and $\operatorname{sex}(\mathrm{HR}=1.69,95 \% \mathrm{CI}=1.27-2.24)$.

\section{Discussion}

The purpose of this paper was to evaluate the weight of a biological predictor (telomere length) alone and compared to other well known health predictors of 5-year mortality after discharge of very elderly patients hospitalized in acute care. It 
HEALTH PREDICTORS' SURVIVAL

Table 2

Univariate and full multiple Cox regression predicting 5-year mortality $(\mathrm{n}=444)$. All independent variables are continuous unless otherwise specified

\begin{tabular}{|c|c|c|c|c|c|c|c|c|c|}
\hline \multirow{2}{*}{ Outcome } & \multirow{2}{*}{ Independent variables } & \multicolumn{3}{|c|}{ Univariate Cox regression } & \multicolumn{5}{|c|}{ Full Multiple Cox regression } \\
\hline & & Crude HR & $95 \% \mathrm{CI}$ & p & $\mathrm{R} 2(\%)$ & Adjusted HR & $95 \%$ CI & $\mathbf{p}$ & $\mathrm{R} 2(\%)$ \\
\hline \multicolumn{10}{|c|}{$\begin{array}{l}\text { Death at } 60 \text { months } \\
(\mathrm{n}=263)\end{array}$} \\
\hline & Age & 1.07 & $1.05-1.09$ & $<0.001$ & 9.5 & 1.06 & $1.03-1.08$ & $<0.001$ & \\
\hline & Sex male & 1.52 & $1.17-1.98$ & 0.002 & 1.9 & 1.69 & $1.27-2.24$ & $<0.001$ & \\
\hline & Telomere length & & & & 0.2 & & & & \\
\hline & lower tertile & 1.04 & $0.76-1.40$ & 0.815 & & 0.75 & $0.55-1.04$ & 0.082 & \\
\hline & medium tertile & 1.00 & -- & -- & & & & & \\
\hline & upper tertile & 1.06 & $0.77-1.44$ & 0.726 & & 0.95 & $0.69-1.31$ & 0.771 & \\
\hline & $\operatorname{BMI}\left(\mathrm{kg} / \mathrm{m}^{2}\right)$ & & & & 1.6 & & & & \\
\hline & $<20$ & 1.15 & $0.71-3.62$ & 0.369 & & 1.17 & $0.83-1.65$ & 0.383 & \\
\hline & $20-25$ & 1.00 & -- & -- & & 1.00 & -- & -- & \\
\hline & $25-30$ & 0.96 & $1.82-7.53$ & 0.791 & & 0.86 & $0.62-1.19$ & 0.364 & \\
\hline & $>30$ & 0.55 & $0.35-0.86$ & 0.009 & & 0.60 & $0.37-0.98$ & 0.042 & \\
\hline & MNA & & & & 0.5 & & & & \\
\hline & & 0.96 & $0.92-1.00$ & 0.071 & & 0.99 & $0.94-1.05$ & 0.734 & \\
\hline & Albumin $(g / l)$ & & & & 1.5 & & & & \\
\hline & $\mathrm{ADL}$ & 0.97 & $0.95-0.99$ & 0.007 & 2.3 & 0.97 & $0.95-1.00$ & 0.031 & \\
\hline & & 0.84 & $0.76-0.93$ & 0.001 & & 1.00 & $0.87-1.16$ & 0.949 & \\
\hline & IADL & & & & 5.9 & & & & \\
\hline & & 0.87 & $0.82-0.92$ & $<0.001$ & & 0.91 & $0.84-0.98$ & 0.015 & \\
\hline & GIC & & & 8.8 & & & & & \\
\hline & Class $1+2$ & 1.00 & -- & -- & & & & & \\
\hline & Class 3 & 1.64 & $1.01-2.66$ & 0.047 & & 1.24 & $0.75-2.06$ & 0.389 & \\
\hline & Class 4 & 3.85 & $2.29-6.47$ & $<0.001$ & & 2.45 & $1.40-4.28$ & 0.002 & \\
\hline & Demented vs cognitively normal & 1.27 & $1.00-1.62$ & 0.053 & 0.6 & 0.88 & $0.66-1.16$ & 0.365 & \\
\hline
\end{tabular}

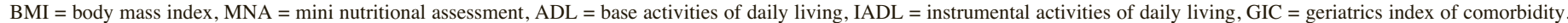
Bold entries $=$ relevant results.

was hypothesized that poor health variables exceed biological factors like telomere length measure. This study confirmed the importance of disability, comorbidity and malnutrition as specific independent predictors in a very old population. One of the main strengths of this study was the standardized comprehensive assessment: the same geriatrician scored the presence and the extent of comorbidity for all patients, the same neuropsychologist carried out a systematic, complete neuropsychological assessment of all the included patients, increasing the accuracy of cognitive diagnosis, the same nurse scored functional and nutritional tools and finally the same biologist assessed the leukocyte telomere length.

Several studies have examined telomere length as determinant of mortality in the elderly. There is considerable inconsistency in the current literature. Some reports have shown associations of shorter telomere length with lower survival: Cawthon and colleagues (9), in their study of individuals 60 years old or older, demonstrated that the overall mortality rate of persons with short telomeres was nearly double that of individuals with long telomeres; Bakaysa et al. (30) reported that twins with shorter telomere length have three times the risk of death compared with their co-twins with longer telomere length. In contrast other studies showed no association between leukocyte telomere length and survival in older individuals' aged more than 85 years $(11,12)$. More recently, Terry et al. had examined telomere length in centenarians in good health versus poor health. Healthy centenarians had significantly longer telomeres than did unhealthy centenarians $(p=0.0475)(31)$. They have demonstrated that investigations of the association between telomere length and exceptional longevity must take into account the health status of the individuals and have raised the possibility that perhaps it is not exceptional longevity but one's function and health that may be associated with telomere length. Our results confirmed this hypothesis.

In our population of very old patients, a 5-year mortality rate of almost $60 \%$ was found after discharge. This rate was similar to that reported in previous studies. Age per se is a well-known negative prognostic risk factor for death and explained almost $10 \%$ of the variance of the outcome in this study. Nonetheless, higher comorbidity, poor functional and nutritional status were factors that negatively affected survival. Similarly to our results, previous studies have shown that worse functional status prior to and at hospital admission is associated with a higher short and long-term mortality $(32,33)$ as well as higher comorbidity scores and worse nutritional status $(34,35)$.

Curiously, in this study, the univariate model shows only a trend regarding dementia as a predictor of 5-year mortality. This trend had completely disappeared when all the variables were added in the full model. On the contrary, many studies have examined survival in relation to dementia and the majority has reported that dementia increases the risk of death compared 


\section{JNHA: CLINICAL NEUROSCIENCES}

to no dementia $(36,37)$. Recently, a Danish population-based cohort study (14 years of follow-up) involving 3,065 nondemented and 234 demented at baseline, showed that the hazard ratio of death (95\% confidence interval) increased from $1.82(1.55-2.14)$ for the very mildly demented to 9.52 (6.6013.74) for the severely demented subjects (38). The majority of these studies are population based and have examined survival from the time of diagnosis of dementia, whereas our study, which was not designed for this purpose, was based on a selected group in a clinical setting and $42 \%$ of the cohort had dementia diagnosis at baseline.

\section{Figure 1}

Kaplan-Meier survival curves according to the observed variables. Marks represent censored observations
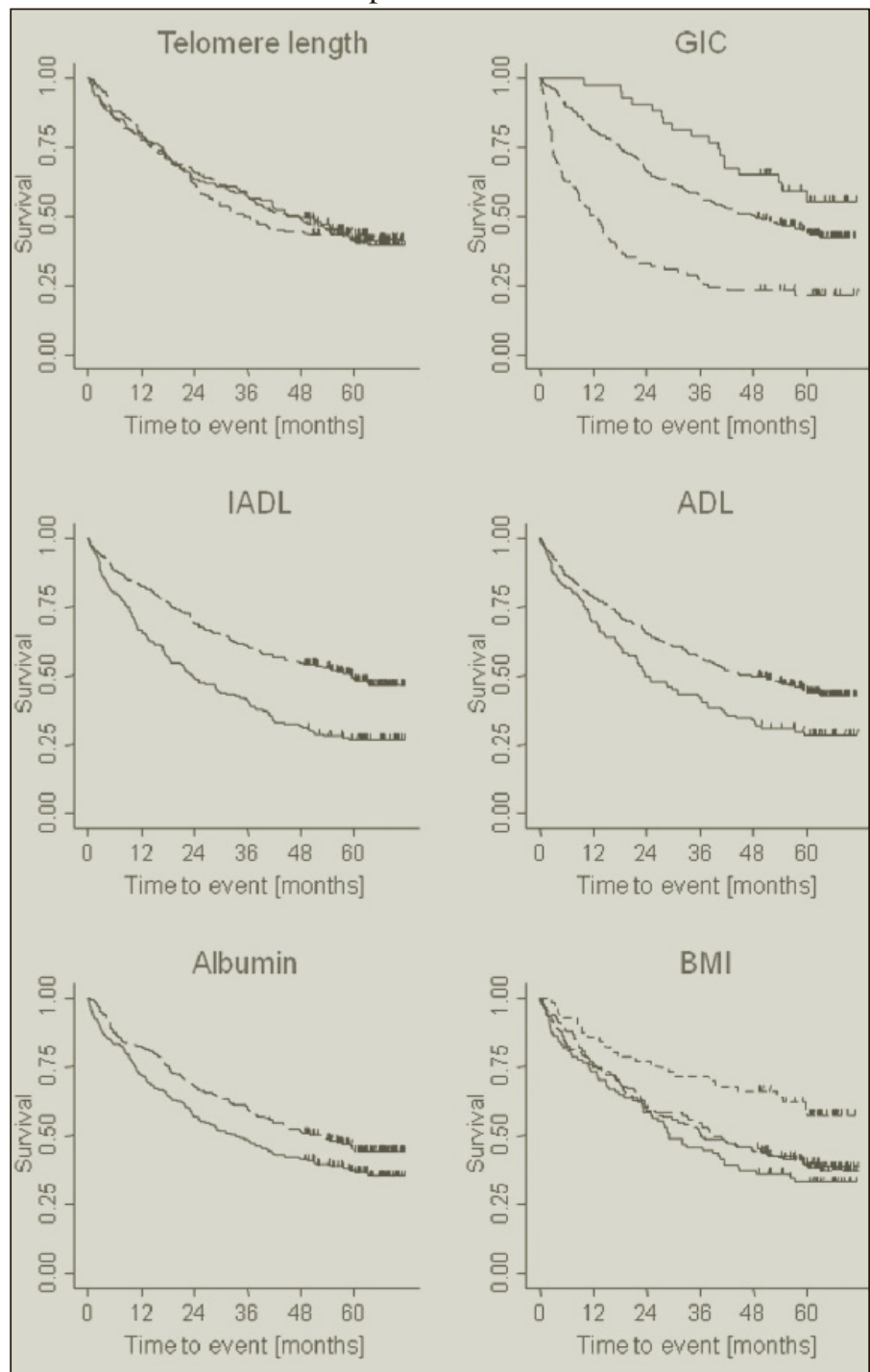

Telomere length (lower tertile: black line; medium tertile: long dashed line; upper tertile: dashed line); GIC = geriatrics index of comorbidity (class 1-2: black line; 3 : long dashed line; 4: dashed line); IADL $=$ instrumental activities of daily living, $\mathrm{ADL}=$ base activities of daily living and Albumin = albumin level $\mathrm{g} / \mathrm{l}$ ( $\leq$ median: black line; $>$ median: long dashed line $)$, BMI = body mass index $\left(\mathrm{kg} / \mathrm{m}^{2}\right)(<20$ : black line; $20-25$ : long dashed line; 25-30: dashed line; $>30$ short dashed line).
Our study has some limitations. First, since it focused on hospitalized elderly patients, it is likely that it is difficult to generalize its conclusions to institutionalized and community dwelling subjects. Second, only one center was involved so the results have to be confirmed in others centers. Third the enrolled patients were very old, acutely ill, and had a high burden of comorbidities.

In conclusion, in this cohort of oldest old, neither leukocyte telomere length nor the presence of dementia are predictors of 5 -year survival whereas the weight of multiple comorbidity conditions, nutritional and functional impairment are. Hospital discharge planning and prognosis can help physicians and family members plan for the care of patients who may be at increased risk of adverse outcomes in the coming years, especially regarding discussions of goals of care, treatment preferences, advance planning, and clinical therapeutic options. Hospitalization therefore may present a key trigger point to identify persons at greatest risk for mortality in the years following discharge.

Acknowledgments: We would like to thank the teams of Mrs. O. Baumer, L Humblot and M Cos for technical assistance.

Funding/Support: This work was supported by grants from the Swiss National Science Foundation (3200B0-102069) and from the Swiss Foundation for Ageing Research (AETAS).

Disclaimer: No author received any consultancy fees or has any company holdings or patents. There are no conflicts of interest.

\section{References}

1. Wong JM, Collins K. Telomere maintenance and disease. Lancet 2001; 362:983-988.

2. Harley CB, Futcher AB, Greider CW. Telomeres shorten during ageing of human fibroblasts. Nature 1990; 345:458-460.

3. Slagboom PE, Droog S, Boomsma DI. Genetic determination of telomere size in humans: a twin study of three age groups. Am J Hum Genet 1994; 55: 876-882.

4. Martens UM, Brass V, Sedlacek L. Telomere maintenance in human B lymphocytes. Br J Haematol 2002; 119:810-818.

5. Allsopp RC, Vaziri H, Patterson C, Goldstein S, Younglai EV, Futcher AB et al. Telomere length predicts replicative capacity of human fibroblasts. Proc Natl Acad Sci USA 1992; 89:10114-10118.

6. Lindsey J, McGill NI, Lindsey LA, Green DK, Cooke HJ. In vivo loss of telomeric repeats with age in humans. Mutat Res 1991; 256:45-48.

7. Houben JM, Moonen HJ, van Schooten FJ, Hageman GJ. Telomere length assessment: biomarker of chronic oxidative stress? Free Radic Biol Med 2008; 44:235-246.

8. Njajou OT, Cawthon RM, Damcott CM, Wu SH, Ott S, Garant MJ et al. Telomere length is paternally inherited and is associated with parental lifespan. Proc Natl Acad Sci USA 2007; 104:12135-12139.

9. Cawthon RM, Smith KR, O'Brien E, Sivatchenko A, Kerber RA. Association between telomere length in blood and mortality in people aged 60 years or older. Lancet 2003; 361:393-395.

10. Bischoff C, Graakjaer J, Petersen HC, Hjelmborg JB, Vaupel JW, Bohr Vet al. The heritability of telomere length among the elderly and oldest-old. Twin Res Hum Genet 2005; 8:433-439.

11. Bischoff C, Petersen HC, Graakjaer J, Andersen-Ranberg K, Vaupel JW, Bohr VA et al. No association between telomere length and survival among the elderly and oldest old. Epidemiology 2006; 17:190-194.

12. Martin-Ruiz CM, Gussekloo J, van Heemst D, von Zglinicki T, Westendorp RG. Telomere length in white blood cells is not associated with morbidity or mortality in the oldest old: A population-based study. Aging Cell 2005; 4:287-290.

13. Njajou OT, Hsueh WC, Blackburn EH, Newman AB, Wu SH, Li R et al. Association between telomere length, specific causes of death, and years of healthy life in health, aging, and body composition, a population-based cohort study. J Gerontol A Biol Sci Med Sci 2009; 8:860-864.

14. Zekry D, Herrmann FR, Grandjean R, Meynet MP, Michel JP, Gold G, Krause KH. Demented versus non-demented very old inpatients: the same comorbidities but 


\section{HEALTH PREDICTORS' SURVIVAL}

poorer functional and nutritional status. Age Ageing 2008; 37:83-89.

15. Zekry D, Herrmann FR, Grandjean R, Vitale AM, De Pinho MF, Michel JP et al. Does dementia predict adverse hospitalization outcomes? A prospective study in aged inpatients. Int J Geriatr Psychiatry 2009; 24:283-291.

16. Zekry D, Herrmann FR, Irminger-Finger I, Ortolan L, Genet C, Vitale AM et al Telomere length is not predictive of dementia or MCI conversion in the oldest old. Neurobiol Aging 2010; 31:719-20.

17. Hultdin M, Grönlund E, Norrback K, Eriksson-Lindström E, Just T, Roos G Telomere analysis by fluorescence in situ hybridization and flow cytometry. Nucleic Acids Res 1998; 26:3651-3656.

18. Rubenstein LZ, Harker JO, Salva A, Guigoz Y, Vellas B. Screening for undernutrition in geriatric practice: developing the short-form mini-nutritional assessment (MNA-SF). J Gerontol A Biol Sci Med Sci 2001; 56:366-372.

19. Katz S, Ford AB, Moskowitz RW, Jackson BA, Jaffe MW. Studies of illness in the aged. The index of ADL: a standardized measure of biological and psychological function. JAMA 1963; 185:914-919.

20. Lawton MP, Brody EM. Assessment of older people: self-maintaining and instrumental activities of daily living. Gerontologist 1969; 9:179-186.

21. Zekry D, Hermont Loures Valle B, Esposito F, Michel JP, Gold G, Krause KH, Herrmann FR. Prospective comparison of six comorbidity indices as predictors of 5 years post hospital discharge survival in the elderly. Rej Res 2010; Sept 6, PMID: 20818930.

22. Rozzini R, Frisoni GB, Ferrucci L, Barbisoni P, Sabatini T, Ranieri P et al. Geriatric Index of Comorbidity: validation and comparison with other measures of comorbidity. Age Ageing 2002; 31:277-285.

23. Folstein MF, Folstein SE, MacHugh PR. Mini Mental State: a practical method for grading the cognitive state of patients for the clinician. J Psychiatr Res 1975; 12:189198

24. Solomon PR, Hirschoff A, Kelly B, Relin M, Brush M, DeVeaux RD, Pendlebury WW. A 7 minute neurocognitive screening battery highly sensitive to Alzheimer's disease. Arch Neurol 1998; 55:349-355.

25. Robert PH, Schuck S, Dubois B, Olié JP, Lépine JP, Gallarda T et al. Screening for Alzheimer's Disease with the Short Cognitive Evaluation Battery. Dement Geriatr Cogn Disord 2003; 15: 92-98.

26. American Psychiatric Association. 2000. Diagnostic and Statistical Manual of Mental Disorders, 4th Ed Text Revision (DSM IV-TR). American Psychiatric Association:
Washington, DC.

27. McKahnn G, Drachman D, Folstein M, Katzman R, Price D, Stadlan EM. Clinical diagnosis of Alzheimer's disease: report of the NINCDS-ADRDA Work Group under the auspices of the Department of Health and Human Services Task Force on Alzheimer's Disease. Neurology 1984; 34:939-944.

28. Roman GC, Tatemichi TK, Erkinjuntti T, Cummings JL, Masdeu JC, Garcia JH et al. Vascular dementia: diagnostic criteria for research studies: report of the NINDSAIREN International Workshop. Neurology 1993; 43:250-260.

29. Royston P. Explained variation for survival models. The Stata Journal 2006; 6:83-96.

30. Bakaysa SL, Mucci LA, Slagboom PE , Boomsma DI, McClearn GE, Johansson B, Pedersen NL. Telomere length predicts survival independent of genetic influences. Aging Cell 2007; 6:769-774.

31. Terry DF, Nolan VG, Andersen SL, Perls TT, Cawthon R. Association of longer telomeres with better health in centenarians. J Gerontol A Biol Sci Med Sci 2008; 63:809-812.

32. Covinsky KE, Justice AM, Rosenthal GE, Palmer R, Landefeld CS. Measuring prognosis and case mix in hospitalized elders: the importance of functional status. J Gen Intern Med 1997; 12:203-208.

33. Inouye SK, Peduzzi PN, Robison JT, Hughes JS, Horwitz RI, Concato J. Importance of functional measures in predicting mortality among older hospitalized patients. JAMA 1998; 279:1187-1193.

34. Espaulella J, Arnau A, Cubí D, Amblàs J, Yánez A. Time-dependent prognostic factors of 6-month mortality in frail elderly patients admitted to post-acute care. Age Ageing 2007; 36:407-413.

35. Drame M, Jovenin N, Novella JL, Lang PO, Somme D, Laniece I et al. Predicting early mortality among elderly patients hospitalised in medical wards via emergency department: the SAFES cohort study. J Nutr Health Aging 2008; 12:599-604.

36. Tschanz JT, Corcoran C, Skoog I, Khachaturian AS, Herrick J, Hayden KM et al. Dementia: the leading predictor of death in a defined elderly population: the Cache County Study. Neurology 2004; 62:1156-1162.

37. Ganguli M, Dodge HH, Shen C, Pandav RS, DeKosky ST. Alzheimer disease and mortality: a 15-year epidemiological study. Arch Neurol 2005; 62:779-784.

38. Andersen K, Lolk A, Martinussen T, Kragh-Sørensen P. Very mild to severe dementia and mortality: A 14-year follow-up - The Odense study. Dement Geriatr Cogn Disord 2010; 29:61-67. 